\title{
La vida de María Bautista y de sus milagros, sus adversidades y su ascensión a los cielos
}

\author{
The life of María Bautista and her Miracles, \\ her Adversities and her Ascension to Heaven
}

\author{
Martina Vinatea \\ Universidad del Pacífico \\ vinatea_rm@up.edu.pe
}

\section{RESUMEN}

Este artículo describe el manuscrito, fechado en 1664, que recoge la vida de la Venerable madre María Bautista del convento de las Comendadoras de Santiago de Toledo como una biografía o «vida» de monjas. Las «vidas» de monjas fueron obras escritas dentro del convento que, a la sazón, era el espacio privilegiado para la escritura femenina, y fueron concebidas como discursos edificantes. La biografía de María Bautista, parte crónica, parte discurso edificante, recoge la estructura básica de este tipo de discurso y al construir un relato ejemplificador, se erige un modelo de santidad cuya finalidad última es desarrollar el paradigma de la «esposa de Cristo».

Palabras Clave: María Bautista; «vidas»; biografías; monja; siglo XVII; escritura femenina.

\section{ABSTRACT}

This paper describes the manuscript, dated 1664, which reflects the Venerable Mother María Bautista's life from the Commanders of Santiago de Toledo's convent as a biography or nuns' «life». Nuns' «lives» were written in the convent, which at that time was a privileged space for women's writing intended as edifying narrative. Mary Baptist's biography, part chronicle, part inspirational discourse, shows the basic structure of this kind of speech and when an exemplary narrative is built, stands a model of holiness whose ultimate goal is to develop the paradigm of «Christ's wife».

Key words: Sacred Biography; María Bautista; «Lives»; Nun; 17th Century; Female Writing.

El propósito de este artículo es informar el hallazgo y describir el manuscrito que recoge la vida de la Venerable madre María Bautista del convento de las Comendadoras de Santiago de Toledo e insertar el mencionado relato dentro de las llamadas biografías o «vidas» de monjas, relatos que se nutren de las hagiografías que toman como modelos la Vita Christi o Vita Mariae.

Copyright: (C) 2016 CSIC. Este es un artículo de acceso abierto distribuido bajo los términos de una licencia de uso y distribución Creative Commons Attribution (CC-by) España 3.0. 
Como bien ha estudiado Sonia Herpoel en múltiples artículos y en su libro A la zaga de Santa Teresa: autobiografías por mandato (1999), las «vidas» de monjas fueron obras escritas dentro del convento que, a la sazón, era el espacio privilegiado para la escritura femenina (Caballé, 2005: 49-62; Loreto, 2006: 93-119), y fueron concebidas como discursos edificantes. Este género parte de un modelo aceptado por la comunidad: la autobiografía de Santa Teresa que sentó las bases de los textos que recogen las «vidas» de monjas.

Si bien la Vida de María Bautista no es una autobiografía como las muchas estudiadas por Herpoel, ya que no lo escribe María Bautista, sino otra monja del convento: María de Santa Isabel; sí podemos analizarla bajo parámetros similares y admitir las afirmaciones generales respecto de las «vidas» de monjas. Sin embargo, anotaremos algunas particularidades del texto que nos parecen relevantes.

Así, en primer lugar, conviene indicar las razones por las que las monjas escribieron sus propias biografías o la de alguna religiosa de su comunidad, que es el caso que trabajamos: la necesidad de manifestar la pertenencia a un grupo organizado alrededor de la práctica confesional. Esta noción de pertenencia las hace conscientes de la fuerza persuasiva de su discurso y del derecho que tienen de ser escuchadas (Herpoel, 1998: 284-286). Asimismo, las religiosas tienen la expectativa de que los textos auto o biográficos escritos, como modelos donde destacan la imitatio y la elocutio, pueden colaborar con el afán proselitista de la Iglesia Católica presente con renovada fuerza desde Trento; sin embargo, en realidad, son textos poco reconocidos, son considerados como una producción menor y probablemente esta haya sido la causa de la desaparición de muchos archivos conventuales (Ferrús, 2007: 78).

Los textos que recogen las «vidas» de monjas presentan una estructura común: el lugar de nacimiento, la historia de sus ancestros (cristianos viejos), la visión que las vincula con una suerte de predestinación divina, la temprana vocación y su lucha por alcanzarla, la profesión de fe, la historia del convento, los santos a los que son devotas, las penitencias corporales, las señales que Dios le envía para que se sienta «elegida», los milagros obrados, que van configurando su santidad y la muerte en «olor de santidad». De este modo, la «vida» completa se convierte en una respuesta continua al llamado divino. Ejemplos de esta estructura se pueden observar en las autobiografías estudiadas por Herpoel o por Thomas Hefferman (1992: 22-25) y calzan perfectamente con las partes que constituyen la Vida de María Bautista.

Basadas en informaciones orales o escritas que nunca se olvidan de acreditar (Romero, 2001: 217-227), las crónicas de convento y las «vidas» de monjas suelen mantenerse como manuscritos en forma de «cuadernos de mano» $\mathrm{y}$, a menudo, sirven como material en bruto para que los confesores y los prelados elaboren sus materiales hagiográficos sin mencionar las fuentes (Glantz, 1992: 227-243). 


\title{
VIDA DE MARÍA BAUTISTA
}

El manuscrito, fechado en 1664, que recoge la vida de María Bautista se encuentra en el archivo de la Orden de las Comendadoras de Santiago en Toledo y gracias a la gentileza y confianza depositada en mí por la Madre María Lucía Girón González, abadesa del convento, pude digitalizar y luego transcribir.

La portada del manuscrito presenta la siguiente información:

\begin{abstract}
Maravillosa vida y prodigiosas virtudes de la Venerable María Bautista, Religiosa de segundo hábito (o como llaman los establecimientos) Sergenta, en el religiosísimo excelentísimo convento de Santa Fe, la Real, de San Santiago de la ciudad de Toledo. Escribió Sor María de Santa Isabel religiosa del mismo hábito y convento, por especial devoción y afecto que la tuvo, en el año de 1664, que fue el año siguiente de la muerte de la venerable madre, y para que no consuma el tiempo y puedan conservarse en lo futuro memorias tan apreciables y tan excelentes prodigios, le obligó su devoción a escribir esta obra.
\end{abstract}

Debe observarse que en esta presentación no se indica, como es habitual, el deseo de «poner por obra un acto de obediencia» impuesto por los confesores. Más bien manifiesta el deseo de la monja escritora, María de Santa Isabel, de que no se pierda el valor ejemplificador de la «vida» de María Bautista. Es decir, como si se tratase de una decisión personal. Luego veremos que en la introducción ya se menciona la importancia que los confesores dieron a la «vida» de la monja. Considero que la Vida de María Bautista revela un proyecto vinculado con la orden de las Comendadoras que podría estar relacionado con el proceso de beatificación de doña Sancha de Alfonso (Barrios Moneo, 2001: 39-45) o quizás con la afirmación de Toledo como la capital espiritual del imperio español ya que había dejado de ser el centro imperial ${ }^{1}$.

Después de la portada, en la primera hoja, están escritas las siglas AMCS/ 31 con tinta de color distinto del resto del documento. Clasificación que significa lo siguiente: Manuscrito N. ${ }^{\circ} 31$ del Archivo del Monasterio de las Comendadoras de Santiago.

Se trata de un manuscrito de 96 folios, in quarto, papel, $208 \times 141 \mathrm{~mm}$, en excelente estado de conservación. Hay una sola letra de mediados del siglo XVII, tanto en el cuerpo como en las anotaciones marginales. La foliación en su mayor parte es contemporánea al manuscrito, escrita en tinta y por la misma mano que el texto. Sin embargo, a partir del folio 83r, la foliación es con otra tinta y otra mano que corresponde a la persona que escribió las siglas AMCS/31 [Archivo Monasterio Comendadoras de Santiago] de la primera hoja, es decir, una mano moderna que posiblemente ordenó el archivo y revi-

\footnotetext{
${ }^{1}$ Debe recordarse que durante gran parte del siglo XVI, Toledo fue la sede de la corte y catedral primada de la Iglesia. En 1561, Felipe II traslada la corte a Madrid y se produce una involución de la ciudad imperial. Toledo a partir del siglo XVII pasa de ser una ciudad palaciega a ser una ciudad conventual.
} 
só los documentos. Es importante resaltar que las mismas siglas aparecen en el extremo derecho del folio 83r. Las dos primeras hojas están sin foliar.

El manuscrito no tiene elementos decorativos, pero las hojas, a partir del primer folio numerado, presentan un marco y las anotaciones hechas por la autora, se encuentran fuera de este. A lo largo del autógrafo, se advierten dos tipos de correcciones: palabras tachadas y corrección al margen y texto sobrescrito, siempre por la misma mano.

Las dos hojas sin foliar contienen una presentación del texto, estas hojas no tienen el marco de las foliadas. La presentación consigna datos sobre la fecha de muerte de la venerable María Bautista, 31 de diciembre de 1663, y la fecha de inicio del escrito: 8 de marzo de 1664.

La historia de la venerable madre María Bautista se inicia en el primer folio numerado y tiene las siguientes partes que se corresponden con los paradigmas de las vidas de monjas:

- Patria y padres de la sierva de Dios (ff. 1r-4v).

- De cómo entró en este Real convento de Santa fe y su fundación (ff. 5r-8r).

- Entra la Venerable María Bautista por seglar (ff. 8v-14r).

— Toma hábito la Sierva de Dios María Bautista (ff. 14v-24r).

- Traen el cuerpo de la Señora Infanta doña Sancha Alfonso del Real convento de Santa Eufemia de los Cozuelos en las montañas a este Real de Santa Fe de Toledo (ff. 25r-28r).

- Síguese la disposición que hizo de lo que sabía y entendía de la Señora Infanta con el mismo estilo que está escrita en los remisoria de su beatificación (ff. 28r-34r).

- De los santos que tenía por devotos (ff. 34r-41r).

- Devoción que la Sierva de Dios María Bautista tenía con su Santísima Madre (ff. 41r - 45v).

- De algunas almas del purgatorio que pedían a la Sierva de Dios las socorriese con oración y decía de otras que estaban en el cielo (ff. 46r-59r).

- Maravillas que obró Dios por la intercesión de esta su Sierva y apariciones que tuvo (ff. 59v-96r).

Como se ve, La vida de María Bautista presenta la estructura habitual de las obras de este tipo, porque seguramente fueron muchas las «vidas» que leyó la monja escritora. Si consideramos que para el año 1664 ya se habían escrito cientos de ellas, es lógico pensar que se siguiera el patrón habitual.

\section{INTRODUCCIÓN}

En la introducción del texto que presenta las hojas sin foliar, se consigna el propósito que se persigue al escribir esta biografía: 
que los confesores ponderando lo raro y prodigioso de sus penitencias, mortificaciones, contemplación y unión con Dios de cuya majestad divina recibía singulares mercedes y favores no se hallasen obligados a escribir una parte de lo que pudiera servir de ejemplo para los pecadores y de aliento para los que procuran servir a Dios [...] me ha parecido darme ocupación tan devota como será recoger en este breve volumen de papel las noticias que viven en esta casa ya de tradición y ya de la evidencia y lo que más cierto y verosímil pueda hallar de tan raros y admirables prodigios como todo el mundo experimentaba en esta sierva de Dios... (Primera y segunda páginas sin foliar del manuscrito AMCS/31).

Resulta llamativo observar que, al menos en apariencia, los confesores, a pesar de ser conscientes de que se encontraban ante un caso excepcional, no fueron quienes encargaron escribir la biografía de la Sierva de Dios, sino que la labor fue asumida por propia iniciativa por María de Santa Isabel, quien tenía las condiciones necesarias para la escritura, pues era poeta ${ }^{2}$. Pareciera que la escritora descubre la necesidad imperiosa de que quede huella de las virtudes y obras de María Bautista. Esta necesidad está avalada por los numerosos antecedentes provenientes de las órdenes religiosas de todo el mundo hispánico 3 .

En las dos hojas que siguen, abunda la adjetivación hiperbólica referida a la figura modélica y las virtudes de la madre María Bautista, como modo de justificar por qué se escribe la biografía y la intención de que quede como un legado para la posteridad, pues María Bautista, esposa de Cristo, es un proyecto de santidad y su vida exige una retórica hagiográfica. La vida de la monja es base de un proyecto religioso y también político. La retórica de la biografía debiera ser persuasiva por si pudiera realizarse un futuro proceso de beatificación de María Bautista o para ayudar al proceso de doña Sancha de Alfonso.

\section{PATRIA Y PADRES DE LA SIERVA DE DIOS (FF. 1R-4V)}

De acuerdo con el texto, la madre María Bautista nació, cerca de 1575, en la localidad de Rejas, perteneciente a la Villa de Madrid. Sus padres fueron Pascual García y Ana Moreno y su nombre en el siglo fue María. La biógrafa asegura que «como Dios quiso tomarla por instrumento de sus grandes maravillas, aunque en lo natural no era hermosa ni de buen talle, bien que el color blanco y purpúreo daba gracia al semblante» (f. 3v-4r). Quedó huérfana muy pequeña y fue acogida por unos tíos cuya casa era «muy abastecida».

${ }^{2}$ El nombre literario de Sor María de Santa Isabel fue Marcia Belisarda, tal como lo pruebo en la edición anotada de la obra poética de María Fernández López, nombre en el siglo de la monja escritora (Fernández López, 2015: 54-69).

${ }^{3}$ Cfr. las «vidas» de Ana de san Bartolomé, Francisca Josefa de la Concepción del Castillo, María de San José, Úrsula Suárez y Úrsula de Jesús solo por mencionar ejemplos recientemente trabajados. 
Desde los infantiles años de su vida hasta los últimos de ella, en que se conservó con tan vigilante dili[gencia] como se dirá después siendo asimismo en la misericordia con el prójimo tan diligente y caritativa que en su infancia (como ella refería muchas veces) salía de la casa de sus tíos (a donde quedó huérfana) y volvía a ella casi desnuda por socorrer al pobre q[ue] lo estaba y sin quien le pudiese vestir con la facilidad que a ella su tío (f. 1v).

Asimismo, como es usual en estas biografías, expresa su amor a Dios con «rigores y disciplinas» y con «ejercicios de virtud en los que se divertía en sus tiernos años», tanto es así que realizó su primer milagro al socorrer la vida de un mozo de su localidad que se había despeñado. Ese milagro hizo que le llevasen tantos enfermos a sanar que pidió la llevaran a Toledo para conseguir entrar en un convento.

\section{De Cómo ENTRÓ EN ESTE REAL CONVENTO DE SANTA FE Y SU FUNDACIÓN (FF. 5R-8R)}

La biógrafa aprovecha este apartado para dar cuenta de la historia del convento y en la parte siguiente realmente se relata su incorporación al convento de Santa Fe de Toledo. Se debe recordar que las Comendadoras o freilas de Santiago son la columna femenina de los caballeros de Santiago (Barrios Moneo, 2001: 11-37).

\section{EnTRA LA Venerable María BAutista POR SEglar (FF. 8V-14R)}

María Bautista entra como seglar al convento y pide ocuparse de la cocina y las religiosas la aceptan «por no saber que el sujeto era para empleos de calidad más alta». Asistía con humildad en la cocina, pero «en vez de cuidar lo que había de comer la comunidad, la hallaban arrobada y después de volver en sí, tan desconsolada y llorosa, que ya viendo que uno y otro parecía costumbre, la retiraban las compañeras a sitio menos público». Ahora bien, estuvo como seglar hasta los treinta años cuando logró obtener su expediente de limpieza de sangre y ser aceptada como monja del convento. La descripción de lo que ocurrió en esos once años más o menos con María Bautista no aparece con claridad en el manuscrito ${ }^{4}$.

\footnotetext{
${ }^{4}$ Resulta importante señalar que existieron otras monjas con el mismo nombre: María Bautista. Una de ellas también fue procesada por la inquisición, pero las fechas que aparecen en el manuscrito estudiado no coinciden con las fuentes sobre el proceso inquisitorial. Al respecto, véase Gómez Castillo (2003) y también, Giordano y Monter (2007).
} 
TOMA HÁBito la Sierva de Dios María BAutista (FF. 14V-24R)

María Bautista recibió el hábito en 1605, a los veintinueve o treinta años y en esta sección se inicia el relato de sus «extremos rigores» habituales en las Vidas de monjas y que, como suele suceder en todos los casos, llegaron a preocupar tanto a sus confesores que la mandaron «fuese con moderación»: traía en los pies tijeras (muchas veces echadas primero a la lumbre), garbanzos y chinas que las demás monjas notaban por su forma de andar; llevaba en el pecho un crucifijo de bronce cuya cruz estaba hecha de púas que lastimaban el lado externo del corazón; se ponía la cera hirviente en las manos y cuando las ampollas empezaban a sanar, se las abría con las uñas para aumentar sus tomentos; realizaba largos ayunos y pasaba días sin beber por recordar la sed de Cristo en el calvario; y no dormía en su cama, sino que se la pasaba en el coro, arrobada, durante toda la noche y para no dormirse, ponía caracoles en sus rodillas. Ferrús nos recuerda que existe una suerte de división de roles dentro del macrorrelato religioso: a los varones les corresponde estudiar, razonar, interpretar los textos, mientras que como las mujeres no podían cumplir estas labores, salvo en casos muy puntuales como el de Teresa de Ávila, Dios — para compensardotaba a las mujeres actitudes particulares y extrañas como oír voces, tener visiones y poder flagelar su cuerpo como recuerdo de la pasión de Cristo y como preparación para la experiencia mística (Ferrús, 2007: 79).

También se narran aquí sus luchas contra el demonio que tomaba la forma de gato o de ratón y entraba al coro en las noches para sacarla de su recogimiento y de todas las tentaciones salió airosa, «por ser tanta su virtud y amor a Dios». Probablemente no haya Vida de monja que no relate sus luchas contra el demonio que afirman su «elección» como esposa de Cristo.

En las dos partes siguientes, se realiza una digresión de la biografía para relatar el traslado de los restos de la Señora Infanta doña Sancha Alfonso del Real convento de Santa Eufemia de los Cozuelos en las montañas a este Real de Santa Fe de Toledo (ff. 25r-28r) y las menciones al expediente de la beatificación de doña Sancha (ff. 28r-34r). En realidad, la vida de María Bautista resulta una suerte de prueba de que el convento de las Comendadoras ha sido elegido para albergar a mujeres santas y, probablemente se emplea como testimonio adicional de algún proceso de beatificación como el de doña sancha de Alfonso.

\section{DE LOS SANTOS QUE TENÍA POR DEVOTOS ${ }^{5}$ (FF. 34R-41R)}

En el manuscrito, la biógrafa reseña los santos a los que celebraba la venerable María Bautista. Resulta importante señalar que María Bautista es «po-

\footnotetext{
${ }^{5}$ Este apartado ha sido desarrollado con mayor amplitud en Martina Vinatea Recoba (2013: 457-466).
} 
limodélica», pues sigue el modelo de varios santos. En la mayoría de «vidas», los santos a los que se tiene devoción son menos y el modelo, por tanto, más sencillo de seguir.

\section{San Bernardo}

La sierva de Dios María Bautista era devotísima de San Bernardo, cuya fiesta hacía cada año y repartía en su nombre algunos dulces entre las religiosas y a todas decía «que era por devoción a la fiesta». Además, a las monjas de su círculo íntimo, a imitación de la Virgen María — que bajaba de los cielos a entregar a monjes y monjas elegidos divinos manjares-, les daba cucharaditas de algún manjar y licor que ella llamaba «celestial» (ff. 34r-34v).

\section{San Martín de Tours}

La madre María Bautista expresaba su devoción por San Martín imitando su gran caridad con los pobres, pues no solo los socorría con cuanto poseía y adquiría de personas caritativas, sino que en una de sus festividades regaló su cama y su manto a una pobre viuda. Cuando la abadesa le increpó su extrema generosidad, María Bautista aseguró que solamente estaba cumpliendo enteramente con el voto de pobreza (ff. $34 \mathrm{v}-35 \mathrm{r}$ ).

\section{Santísimo Sacramento}

Esta devoción es muy importante en el caso de las «esposas de Cristo», pues evidencian el «matrimonio místico». Los días que estaba el Santísimo Sacramento expuesto, María Bautista aguardaba en el coro la oportunidad para cantar al niño y decía: «¿Quién ha visto un niño? Aquí está, aquí está que no está perdido, que es tan grande como su padre, y como el Espíritu Santo», y luego, «parecía perder el juicio y danzaba tan fuera de sí que no parecía poner los pies en el suelo. Finalmente, quedaba arrobada, llena del amor de Dios» (f. 36r).

\section{San Juan Bautista}

En su profesión de fe, elige el nombre del Bautista «de quien era tan apasionada como la que más» ${ }^{6}$. Aseguraba haberlo imitado desde su niñez en lo

\footnotetext{
${ }^{6}$ Recuérdese el enfrentamiento entre monjas devotas de Juan, el Bautista y las devotas de Juan, el Evangelista. En muchos conventos existió una tensa rivalidad hagiográfica entre partidarios del Bautista y seguidores de san Juan Evangelista. Estas disputas sobre cuál de los dos Juanes gozaría de una mayor preeminencia en el reino de los cielos, fueron especialmente vivas en los conventos de monjas donde, por lo general, las religiosas de origen noble solían ser «bautistas» mientras que las menos favorecidas socialmente eran «evangelistas». Cavillac (2003); véase también Mariló Vigil (1986: 250-255).
} 
penitente y retirado. María Bautista establecía otra analogía entre su vida y la del precursor de Cristo: a Juan le quitaron la vida por decir verdades, a María Bautista por decir solo una pretendieron quitarle la honra (que ella aseguraba era tan importante como la vida) y fue examinada por la Inquisición: una señora conocida del convento compró testigos para ganar un juicio. Cuando la madre vio a la señora en la iglesia, desde el coro le dijo, delante de todos los que allí estaban que

mirase que había Dios, juicio e infierno. Por ello, la acusaron al tribunal de la Santa Inquisición, de donde vino un ministro de los superiores a examinar a la Sierva de Dios. Conforme avanzaba el juicio, el inquisidor cada día quedaba más confuso por las muestras que María Bautista daba de virtud y hasta se extrañaba de su deseo de oírla y de verla. La conclusión que el examinador presentó de esta causa fue «decir misa y darle de su mano la comunión (f. 37r).

Dejó así la opinión de la venerable María Bautista «acrisolada y con nueva reputación de santa». Asimismo, María Bautista fue gran imitadora de la humildad de su esposo (Cristo) y, siguiendo los pasos de San Juan, la monja enseñaba a los que deseasen conocer a Dios verdaderamente. Asimismo, como el Bautista se oponía a que lo consideraran el hijo de Dios, la madre María Bautista rechazaba el que la tuviese el mundo por santa (f. 36v).

Tal como asegura Herpoel, la particular sensibilidad del Barroco da lugar a excesos que, en muchos casos, se consideran como conductas divergentes y generan recelo en las autoridades eclesiásticas (Herpoel, 1993: 495). María Bautista no fue la excepción y tuvo que pasar por el examen de la Inquisición.

\section{Santo Domingo}

María Bautista demostraba su devoción por Santo Domingo en su preferencia en confesarse durante toda su vida con religiosos de esa orden, a quienes seguía la sierva de Dios, «para no errar el camino de perfección». Por esto, el demonio en ninguna transformación pudo triunfar «dejando corrido al demonio en las diferentes figuras en que se le presentaba: ya de gato que la iba impidiendo el subir la escalera de su celda y ya de ratón ferocísimo, que en vez de pelo tenía púas y tan fea y espantosa figura que apagó la luz por no verlo». También, María Bautista celebraba a Santo Domingo con la misericordia: jamás se escandalizó ni se admiró de las flaquezas del prójimo (ff. 38v-39r).

Devoción Que la Sierva de Dios María Bautista tenía CON SU SANTíSIMA MADRE (FF. 41R-45V)

María Bautista sentía una enorme devoción por la Santísima Virgen a quien trataba de imitar permanentemente. La monja sostenía que sin la intercesión 
de la Madre de Dios no era posible salvarse, ni conseguir la bienaventuranza. Relata la biógrafa de María Bautista que, una vez, la Virgen María mandó a la sierva de Dios que le quitasen el niño Jesús a una de sus imágenes y la llamasen, por ello, Virgen de la Concepción y así la celebraran con ese título y como única patrona de la orden de las Comendadoras.

Asimismo, cuentan que una imagen diferente y muy pequeña de la Virgen Santísima le habló a la madre María Bautista de este modo: «Sácame de aquí que soy la madre de Dios y estoy escondida». María Bautista puso toda diligencia para que fuese tratada de allí adelante con mayor veneración, como se hizo desde entonces en el convento.

Finalmente, era devotísima del misterio de la Encarnación y el día en que se celebraba esta fiesta, estaba la sierva de Dios fuera de sí. Dicen los confesores que «era tal la unión que tenía María Bautista con Dios que ningún teólogo pudiera darle alcance por encumbrada y dificultosa que era».

\section{Espíritu Santo}

La venerable madre fue una enamorada del Espíritu Santo y en los tres días de su fiesta y otros antecedentes «hacía excesos como loca», aunque más se reprimía y procuraba que el fuego de su amor no «reventase por los sentidos exteriores, su corazón en oración continua, ardiente y fervorosa no se podía contener y salía en público y daba voces publicando las grandezas y maravillas que el mismo Espíritu Santo le enseñaba». Hacía fiesta al Espíritu Santo cada año, con toda solemnidad, repartía regalos entre las religiosas y decía que «como el Espíritu Santo le regalaba sus dones, ella debía regalar a las esposas de Dios aquellos dulces». También, mandó preparar, a su costa, ornamentos diferentes de los de la comunidad para esta fiesta y para otras principales: candeleros de plata, vinajeras, salvillas, macetitas y otras muchas alhajas que sirviesen al culto divino.

La última fiesta que la sierva de Dios María Bautista hizo al Espíritu Santo, la preparó estando cercana a la muerte con la ayuda de una de las monjas. A pesar de su resquebrajada salud, organizó la fiesta. Desde la víspera hasta el último y tercer día de esta pascua, la sierva de Dios parecía

un serafín abrasado en su amor divino: tanto por lo encendido de su rostro, como por el volar por los dos coros, con un rociador de agua de olor (que era de ángeles por estar en su mano) y con él rociaba a todas las monjas, diciendo que hacían oficio angélico alabando a Dios y si el compás del tono de órgano y voces era proporcionado a su oído, danzaba con tanta gracia que parecía su oficio y las reverencias tan a propósito de la letra, como quien meditaba cuanto en ella se incluye, que todo lo entendía, alabando, bendiciendo y adorando a Dios a quien daba gracias perpetuamente por todo lo creado con su mano poderosa (ff. 44r-44v).

Después de esa celebración, quedó arrobada hasta la noche en el coro, a donde las monjas de poca edad procuraban hacer pruebas de su virtud soplando 
el cuerpo de la sierva de Dios que se movía como si fuera una pluma, y en algún momento, por travesura o malicia, le clavaron un alfiler, dolor que no la inmutó, ni sintió, hasta volver en sí, después de un tiempo (ff. 42v-44v).

\section{Santiago apóstol}

Para las fiestas de Santiago que su convento celebraba en grande, al ser su patrón, la madre María Bautista ayudaba con aplausos y alabanzas a las que hacían oficios de sacristana, provisora, maestra de capilla, y todos los demás. Asimismo, por la fama que el coro tenía en la ciudad, muchos toledanos se acercaban a escucharlo, y una vez dijo en voz alta: «Mucho sea servido Dios de la fiesta», «echando con el movimiento cuatro o cinco fuentes de plata al suelo y volviendo a ponerlas en su sitio con tanta brevedad que todo el refectorio quedó pasmado de la palabra y obra y después se sentó reprimiendo lágrimas tiernas y devotas» (ff. 45r-45v).

DE ALGUNAS ALMAS DEL PURGATORIO QUE PEDÍAN A LA SIERVA DE DiOS LAS SOCORRIESE CON ORACIÓN Y DECÍA DE OTRAS QUE ESTABAN EN EL CIELO (FF. 46R-59R)

Víctima de una época en la que las imágenes de la mujer divina y de su vertiente demoniaca se codean (Herpoel, 1993: 500), tuvo la madre María Bautista una visión del infierno, donde vio a un hombre - que ella ya había olvidado- consumirse en el fuego del infierno. También tuvo visiones purgatoriales, donde vio tanto a conocidos como a gente que le habían recomendado. María Bautista hablaba con ellos y todos le pedían oración para que se acortase su paso por el purgatorio. Prima aquí el modelo de intercesión divina trasladado a María Bautista. Lo más llamativo de esta parte es que aseguran se le presentó el sacerdote que la examinó por encargo de la Inquisición y le pidió rezase por él ${ }^{7}$.

MARAVILlAS QUE OBRÓ DIOS POR LA INTERCESIÓN DE ESTA SU SIERVA Y APARICIONES QUE TUVO (FF. 59V-96R)

En el último apartado del manuscrito, se relatan los milagros obrados por la madre María Bautista, su enfermedad, su muerte en olor de santidad y su ascensión al cielo como monja coronada. La biógrafa enumera sin criterio alguno «las maravillas» realizadas por intercesión de María Bautista. Podríamos agruparlos por el tipo de acción del siguiente modo:

\footnotetext{
${ }^{7}$ Este tema ha sido desarrollado en el artículo «Todo el purgatorio sobre sus hombros: María Bautista y la expiación de las almas», en el libro Purgatorios, bajo el sello editorial del Fondo editorial de la Universidad del Pacífico (Vinatea, 2015).
} 
Milagros de sanación: quitó un garabato del ojo de una criada del convento, echo un poco de vino y el ojo quedó sin lesión alguna; salvó a un muchacho que tenía las tripas afuera con darle de comer una bizcotela; curó un dedo gangrenado con agua bendita; y otros casos menores, todos con agua bendita. Sin embargo, concedió la gracia a una importante mujer para que saliera embarazada y le pidió a cambio que enviara un vestido verde para la Virgen; la señora, que no tenía mucha fe ni confianza, le dijo a María Bautista que enviaría el vestido cuando naciera el niño y el niño nació muerto cubierto en una densa agua verde.

Don de la ubicuidad: María Bautista fue vista en Madrid varias veces para consolar afligidos; se le apareció a una mujer que, presa de la desesperación por el maltrato de su marido, estaba a punto de ahorcarse. No solo la salvó, sino que cambió la actitud del marido.

Visiones celestiales: Además de tener las visiones del purgatorio y del infierno antes mencionadas, María Bautista vio una custodia celestial; a la Santísima Trinidad; a la Virgen María; y recibía las visitas de Cristo mismo y cuando esto ocurría, quedaba la celda impregnada de un olor delicioso que nadie podía reconocer.

Otros milagros: amasó un manjar blanco que se había avinagrado y quedó como manjar celestial; conoció una sentencia antes de ser dictada; conseguía cambiar la opinión de los parientes que se negaban a que las doncellas entraran al convento.

Reconocimiento de su valía: Los reyes Felipe III y Margarita de Austria visitaron a la Madre María Bautista; asimismo, el duque de Lerma ${ }^{8}$, y su hijo, el conde de Saldaña; y el duque de Lorena ${ }^{9}$. Los Duques de Lerma y Lorena le pidieron a la madre que rezara por la salvación de sus almas.

La muerte preciosa de María Bautista forma parte de esta sección. A pesar de su frágil estado de salud, la sierva de Dios se encontraba lúcida y recordaba muchos episodios de su vida. Días antes de morir, predijo su muerte y la de su compañera Catalina Gudiel, que murió cuatro horas antes que María

\footnotetext{
${ }^{8}$ Francisco Gómez de Sandoval-Rojas y Borja, más conocido como Francisco de Sandoval y Rojas (1553-1625), I duque de Lerma desde 1599, primer ministro y valido de Felipe III (1598-1622). Su segundo hijo, Diego de Sandoval Rojas, Conde Saldaña, muerto en 1632, fue un reconocido mecenas que dirigió una academia donde participaron Lope de Vega y Cervantes, entre otros.

${ }^{9}$ Carlos IV, Duque de Lorena y de Bar (1604-1675). Fue Duque de Lorena y de Bar de forma intermitente entre 1625 y 1675 . Estuvo confinado en el Alcázar de Toledo de 1654 a 1659.
} 
Bautista. A su velorio y entierro concurrió la mayor parte de la población de Toledo y la comunidad de la Orden de Santiago, en pleno: maestre, caballeros y comendadoras. Antes de que la enterraran, fue preciso que «su confesor defendiese la decencia de su cuerpo que a pedazos querían dejar sin hábito valiéndose de tijeras que tuvieran prevenidas para el efecto», que muchos tuvieron por reliquias.

María Bautista murió en la madrugada del primer día de 1664, en olor de santidad y dos monjas de otra congregación vieron cómo ascendió a los cielos. La reconocieron por el hábito de las comendadoras y dijeron que llevaba una corona preciosísima y toda llena de resplandores.

Como un rasgo particular de la biografía que nos ocupa, llama la atención el hecho de que María Bautista ascienda a los cielos como monja coronada y fuera vista así por monjas de otros conventos. Si bien es cierto la práctica de coronar a las monjas a la hora de su muerte era conocida, no era tan usual en el ámbito peninsular. En Hispanoamérica, sí era práctica común, pues se siguió el modelo de la iconografía de Santa Rosa de Lima, la primera santa del Nuevo Mundo. La biógrafa deja entrever una suerte de coronación divina en el momento de la ascensión.

En suma, la biografía de María Bautista, parte crónica, parte discurso edificante, recoge la estructura básica de este tipo de discurso, sin desmedro de tener algunas particularidades que la distinguen, como el hecho de ser una biografía escrita por una monja que cultivaba la escritura, una reconocida poeta: Marcia Belisarda. La biógrafa no fue obligada por los confesores, sino que parte del deseo personal y comunitario de preservar para la posteridad una historia que se considera digna de ser contada y que podía erigirse en modelo y servir de testimonio y refuerzo en el empeño de beatificar a doña Sancha de Alfonso. Asimismo, resulta particularmente llamativo el hecho de su adscripción a varios modelos de santidad: María Bautista no sigue a un santo, es devota «como la que más» de muchos. Finalmente, como ocurre en el caso de todas las «vidas» de monjas, al construir un relato ejemplificador, se erige un modelo de santidad cuya finalidad última es desarrollar el paradigma de la «esposa de Cristo».

\section{BIBLIOGRAFÍA CITADA}

Barrios Moneo, Alberto (2001). Las Comendadoras de Santiago. Madrid: s. n.

Caballé, Anna (2005), «Biografía y autobiografía: convergencias y divergencias entre ambos géneros», en J.C. Davis e Isabel Burdiel (ed.), El otro, el mismo. Biografía y autobiografía en Europa (siglos XVII-XX). Valencia: Universidad de Valencia, pp. 49-62.

Cavillac, Michel (2003). «La figura de san Juan Bautista en el Guzmán de Alfarache», Melanges de la Casa de Velázquez. 33 (2), pp. 131-163.

Fernández López, María (Marcia Belisarda) (2015). Obra poética completa. Martina Vinatea Recoba (estudio, ed. y notas). New York: IDEA. 
Ferrús, Beatriz (2007). Heredar la palabra: cuerpo y escritura de mujeres. Valencia: Tirant lo Blanch.

Giordano, María Laura y Josep Monter (2007). «Al borde del abismo: falsas santas e ilusas madrileñas en la vigilia de 1640», Historia social. 57 pp. 75-97.

Glantz, Margo (1992). «Sor Juana y otras monjas: la conquista de la escritura», Debate feminista. Año 3, 5, pp. 227-243.

Gómez Castillo, Antonio (2003). «Escrito en prisión. Las escrituras carcelarias en los siglos XVI y XVII», Península. Revista de estudios ibéricos. 0, pp. 147-170.

Hefferman, Thomas (1992). Sacred Biography. New York: Oxford University Press.

Herpoel, Sonja (1993). «La endemoniada de Lerma o visión e imaginación», en Manuel García Martín (coord.), Estado actual de los estudios sobre el Siglo de Oro. Actas del II Congreso Internacional de Hispanistas del Siglo de Oro, 1. Salamanca: Universidad, pp 495500.

Herpoel, Sonja (1998). «Inés de la Encarnación y la autobiografía por mandato», en Jules Whicker (coord.), Actas del XII Congreso de la Asociación Internacional de Hispanistas 21-26 de agosto de 1995, Birmingham, 2. Birmingham: University, pp. 284-291.

Herpoel, Sonja (1999). A la zaga de Santa Teresa: Autobiografías por mandato. Amsterdam: Rodopi.

Loreto, Rosalva (2006). «Los manuscritos confesionales. Un acercamiento a la mística novohispana», Estudios Humanísticos. Historia. 5, pp. 93-119.

Romero Frías, Marina (2001). «Voces entre rejas: escritura femenina en la Cerdeña de finales del siglo XVII», E-Humanista. 18, pp. 217-227.

Vigil, Mariló (1986). La vida de las mujeres en los siglos XVI y XVII. Madrid: siglo XXI.

Vinatea, Martina (2013). «Celebraciones dentro del claustro: la venerable María Baptista y sus devociones», en Mariela Insúa y Martina Vinatea Recoba (ed.), Teatro y fiesta popular y religiosa. Pamplona: Universidad. Biblioteca Áurea Digital, BIADIG, 20.

Vinatea, Martina (2015). "“Todo el purgatorio sobre sus hombros": María Bautista y la expiación de las almas», en Jorge Wiesse (ed.), Purgatorios/Purgatori. Lima: Universidad del Pacífico, pp. 309-322.

Fecha de recepción: 22 de mayo de 2014.

Fecha de aceptación: 6 noviembre de 2014. 